\title{
Evidencias de Cirugía Craneana Prehistórica en Colombia
}

JAIME GOMEZ GONZALEZ

Director del Instituto Neurológico de Colombia

Estudio Anatómico y Radiológico

GONZALO CORREAL URREGO

Datos Antropométricos 
Figura No. 1. Caso No. 1. Trepanación parietal derecha y plastia.

Figuras Nos. 2 y 3. Caso No.1. Radiografías lateral y antero posterior

Figura No.4. Caso No.2. Defecto quirúrgico con pérdida de sustancia parietal izquierda.

Figura No. 5. Caso No. 3. Defecto quirúrgico parietal derecho 
(Cundinamarca) y Sopó (Cundinamarca); en los dos primeros casos se encontró asociación con cerámica cuya tipología se corresponde a la dada para la cultura 作 algunas piezas de evidente manufactura Guane, hecho que sugiere la existencia de contactos culturales con este último grupo.

\section{PRESENTACION DE CASOS}

Caso No. 1

Procedencia: Sopó (Cundinamarca) (1)

Sexo: femenino

Edad: adulta

Número de clasificación $62-1788$

Presenta un defecto circular de 1.4 centímetros de diámetro de la región parieta derecha, a 4 centímetros de la sutura interparietal y a 2.3 centímetros de la coronal (Figura 1). Los bordes del orificio son netos; las superficies vecinas son lisas y no muestran cambios.

El defecto está obturado firmemente por material denso de color gris violáceo que protruye ligeramente el hueso, más hacia el interior que hacia afuera. Las suturas están protruye ligeramente separadas; el estudio radiológico confirma este hecho y revela además la presencia de densidad radio-opaca en el sitio del defecto óseo sin alteraciones del hueso vecino (Figuras 2 y 3 ). E1 hecho de la presencia de una zona densa alrededor del defecto, sugiere la supervivencia del individuo por lo menos algunos meses después de practicado el traumatismo. La silla turca aparece normal.

El análisis químico del material plástico que obtura el defecto corresponde a arcilla silícea con alto contenido ferrítico.

El estudio histológico del hueso vecino al defecto, muestra tejido óseo normal.

Caso No. 2

Procedencia: Belén (Boyacá) (2)

Sexo: femenino

Edad: adulta

Número de clasificación: 72-3566

Presenta defecto circular de 5 centímetros de diámetro con bordes biselados de medio centímetro de ancho a expensas de la tabla externa (Figura 4). El defecto está situado en la región parietal izquierda, al margen anterior al contacto con la sutura coronal; presenta ligera irregularidad en forma de cuña de vértice anterior. Hacia la región fronto orbital se continúa esta irregularidad con superficie rugosa y erosionada de la tabla externa. El margen superior del defecto óseo está a 2 centímetros de la sutura sagital.

(1) Donado por el profesor G. Reichel-Dolmatoff.

(2) El hallazgo ocasional fue efectuado por el señor Abelardo Bautista en la vereda de San José de la Montaña (altura $3.000 \mathrm{~m}$.).

NOTA: El caso No. 1 puede estar originado en lesión traumática. 
Existen otros dos pequeños defectos: uno en el hueso frontal, dos centímetros por encima del reborde orbital izquierdo; tiene forma ovalada, mide $1.4 \mathrm{~cm}$. en sentido transversal y $0.9 \mathrm{~cm}$. de adelante hacia atrás; está en cercana proximidad de la erosión tabular externa descrita anteriormente. El otro defecto es semilunar de concavidad anterior; mide $1.3 \mathrm{~cm}$. en sentido vertical, $0.3 \mathrm{~cm}$. de ancho y $1.9 \mathrm{~cm}$. por debajo y por delante de la craniectomía. Estas zonas de tabla externa erosionada y los do: pequeños defectos los hemos interpretado como producidos por el desgaste natural dol tiempo sobre el hueso.

No se observan en la superficie craneana exterior o inferior otras huellas quirúrgica: fuera de las mencionadas. Las suturas tienen aspecto normal. El piso de la base dol cráneo no ofrece particularidades. La silla turca y las apófisis clinoides tienen su constitución normal.

Las radiografías del cráneo muestran buena conformación ósea con las pérdidas de sustancia descritas, sin cambios en los bordes del hueso. La ausencia de una zona densa alrededor del defecto, sugiere que el deceso del individuo debió ocurrir simultáneamente con la trepanación o poco tiempo después de practicada ésta.

Caso No. 3

Procedencia: Nemocón (Cundinamarca) (3)

Sexo: masculino

Edad: adulto

Número de clasificación: 72-3567

En el parietal derecho se observa un gran defecto óseo con bordes biselados cad circular, con diámetro de $8 \mathrm{~cm}$. que se extiende desde $2 \mathrm{~cm}$. de la sutura coronal hasta 3 $\mathrm{cm}$. de la sutura parieto-temporal, y desde $1 \mathrm{~cm}$. de la fronto-parietal hasta $2.5 \mathrm{~cm}$. de la parieto-epactal; el hueso marginal del defecto en una extensión de $2 \mathrm{~cm}$. hacia lo periferia tiene un color más pálido que el resto de la superficie craneana (Figura 5).

En la porción más inferior del defecto óseo sobre el hueso parietal, extendiéndose del borde óseo a la sutura parieto-temporal, existe una línea de fractura. La superficlo del hueso vecino a la pérdida de sustancia presenta coloración más pálida que el resto de la superficie y forma un halo anémico (de descoloración) que se extiende a $2 \mathrm{~cm}$. de los márgenes del defecto óseo. El lado izquierdo del cráneo está mal conservado y presenta varios defectos no sistematizados.

Las radiografías muestran una deformación por aplanamiento de la región frontul. Los huesos de la bóveda son densos; en el parietal derecho se aprecia la pérdida de le sustancia descrita, sin que se observen alteraciones óseas marginales. Se destac claramente la fractura parietal, no se evidencia el dorso de la silla turca, pero los clinoides anteriores incluso de la silla turca son normales.

\section{Rasgos morfológicos particulares}

\section{Caso No. 3.}

La apreciación de las normas frontal y lateral pone en evidencia la retracción del frontal con deformación oblicua. Visto el cráneo en norma posterior presentu

(3) El hallazgo ocasional fue efectuado en la vereda Villa Tranquilina por el señor Jorge Pinzón, y adquirido por las investigadoras Ann Osborn y Mariana Cardale de Schrimpff, quienes lo 596

plagiocefalia derecha. En esta misma norma se observa la presencia de hueso epactal separado por una sutura amplia y con huesos insulares laterales; también se observa la presencia de hueso apical. La presencia de hueso epactal ya ha sido observada en e Perú por Roca y Graña.

\section{CARACTERES CRANEOMETRICOS}

Número de identificación

Sexo

Edad

1. Diámetro antero-posterior máximo

2. Diámetro bizigomático

3. Diámetro bimastoideo máximo

4. Diámetro bicondíleo

5. Diámetro bigonia

6. Diámetro alvéolo-basilar

7. Diámetro frontal mínimo

8. Diámetro frontal máximo

9. Diámetro naso-mentoniano

10. Diámetro transverso máximo

11. Diámetro ofrio-alveolar

12. Distancia aurículo-bregmática

13. Distancia naso-basilar

14. Altura basio-bregmática

15. Altura naso-alveolar

16. Altura opistio-bregmática

17. Altura de la órbita

18. Anchura de la órbita

19. Anchura inter-orbitaria

20. Anchura de la nariz

21. Altura de la nariz

22. Altura de la apertura piriforme

23. Anchura de la bóveda palatina

24. Longitud de la bóveda palatina

25. Anchura del agujero occipital

26. Longitud del agujero occipital

27. Curva sagital

28. Curva transversal

29. Perímetro horizontal máximo

30. Arco frontal

31. Cuerda frontal

32. Arco parietal

33. Cuerda parietal

34. Arco occipital

35. Cuerda occipital

$\begin{array}{ccc}62-1788 & 72-3566 & 72-3567 \\ \begin{array}{c}\text { Femenino } \\ \text { Adulta }\end{array} & \begin{array}{c}\text { Femenino } \\ \text { Adulta }\end{array} & \begin{array}{c}\text { Masculino } \\ \text { Adulto }\end{array}\end{array}$

111

121

95

101

103

$-$

$-$

96

95

104

137

71

156

30

40
27

27

23
47

35

64

48

28

32

374

-

112

112

101
120

101

142 


\section{RESUMEN DE INDICES CRANEALES Y FACIALES}

Número de identificación

Sexo

Edad

1. Indice craneal horizontal

2. Indice facial-superior

3. Indice gnático de flower

4. Indice nasal

5. Indice orbitario

6. Indice palatino

7. Indice vértico-longitudinal

8. Indice vértico-transversal
62-1788

Femenino

Adulta

$72-3566$

Femenino

Adulta

72-3567

69.51

(dolicocráneo)

47.24

(mesognato)

98.93

102.17
(mesognatt

(mesognato)

55.55

(platirrino)

52.17

(platirrino)

109.37

(hipsiconco)

109.67

(hipsiconco)

Masculino

Adulto

133.33

(braquiesta-

filino)

134.78

(braquiesta-

filino)

-

-

73.78

79.50

(hipsicráneo)

97.11

(mesognato)

48.93

(mesorrino)

133.33

(hipsiconco)

136.17

(braquiesta

filino)

75.27

(hipsicráneo)

\subsection{4}

(acrocráneo)
En el primer cráneo objeto de este estudio, (62-1788), la separación de suturas indica un proceso crónico de hipertensión endocraneana; no hay evidencias suficientes para diagnosticar en términos precisos sobre las razones por las cuales se realizó la intervención en el segundo caso (72-3566). En el tercer cráneo (72-3567), la cirugía se efectuó muy posiblemente para tratar una lesión traumática; esta deducción se basa en la circunstancia de existir una fractura lineal confirmada en la radiografía.

Como quedó expuesto en el estudio general, el primer caso pudo haber sobrevivido algún tiempo después de la práctica quirúrgica, debido a la presencia de una zona densa alrededor del defecto óseo y porque se insinúa un proceso de cicatrización; en los otros dos cráneos objeto de estudio no existe esta evidencia habiéndose producido el deceso simultáneamente con là trepanación o inmediatamente después.

\section{NOTA:}

La ausencia de notación de algunos valores en las tablas de caracteres craneométricos e indices, obedece a la presencia de fracturas óseas por lo cual no se pudieron obtene las mediciones correspondientes.

\section{CONSIDERACIONES FINALES}

El primer caso presentado en este estudio (Número 62-1788), podría ser una muestra de trepanación por técnica de raspado, con bordes lisos y craneoplastia. El segundo y tercer casos (72-3566 y 72-3567), representan craniectomías hechas con utilización del mismo método, pero con bordes en bisel. Las intervenciones fueron realizadas probablemente con fines quirúrgicos en el primer caso. La palidez del hueso en la zona marginal de la craniectomía (caso número 3 ) posiblemente fue ocasionada, por el desprendimiento previo del periostio característica que Weiss ha denominado "Halo Anémico" (Weiss. 1970) 


\section{COLABORACIONES}

Las radiografías del primer caso fueron practicadas por el doctor Gustavo Sánchez; las restantes, en el Departamento de Radiología de la Fundación Shaio. Los estudios histológicos y químicos del primer caso fueron hechos por los doctores Gabriel Ortega y Ernesto Bautista, de la Facultad de Medicina de la Universidad Javeriana.

\section{BIBLIOGR AFIA}

Comas, Juan. Manual de Antropología Física. VII: 351-390. Fondo de Cultura Económica, México, 1957

Facultad de Medicina de la Universidad de Sao Pato. América. En Michoacán. No. 57: 78. 1959

Gómez González, Jaime. “Albores de la Neurocirugía en Colombia”. Universitas Médica (Bogotá) 9 69,1967

Graña F. Rocca, E. y Graña, C. Trepanaciones craneanas en el Perú en la época pre-hispánica Lima, Imprenta Santa María 340 pp. 1954

Mora Rubio- J. "Craneotomías Americanas Precolombinas", Rev. Dirección de Divulgación Cultural Universidad Nacional de Colombia No. 3, p.24. Agosto 1, 1969.

Mora Rubio,J. Comunicación Personal, 1972

Pardal,R. La trepanación craneana en el antiguo Perú. 1935

Pérez de Barradas, José. Manual de Antropologia. Gráficas Rey Atocha 115. Madrid, 1946

Día Médico (Buenos Aires) 7: 1145-1150, 1935

Walker, A.E. "Primitive Trepanation" The begining of Medical History. Transactions \& Studies of the College of Physicians of Philadelphia 4 ser, 26: 99, 1958

Weiss, P. en Texto de Patología. Ed. P. Correa et al.México. Prensa Médica Mexicana. 1a. Ed. pp 26-33. 1970

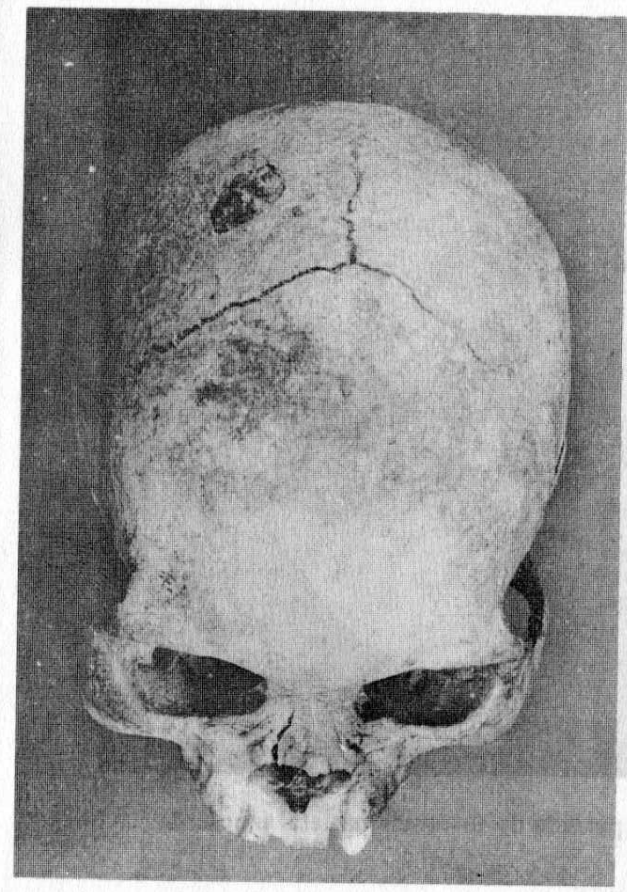

Fig. 1

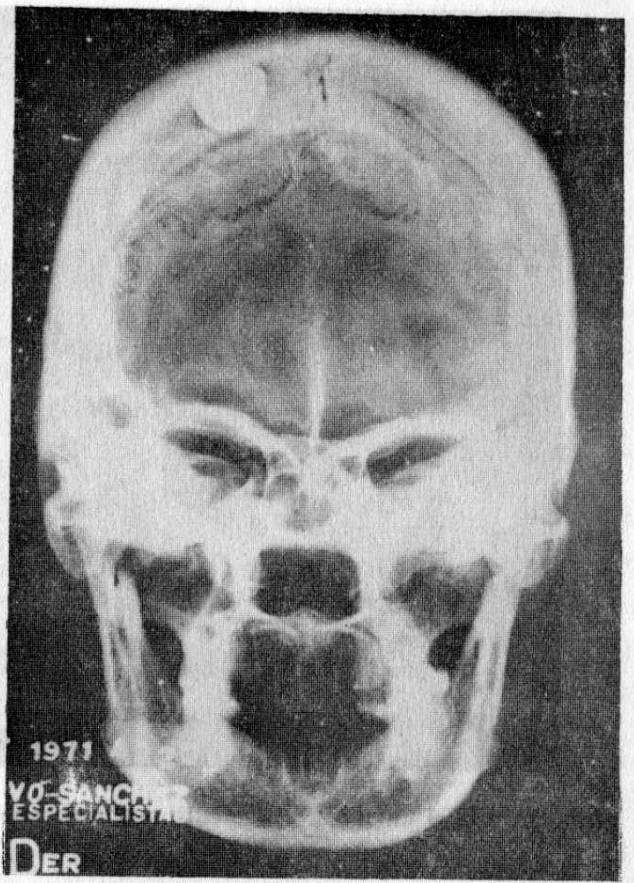

Fig. 2

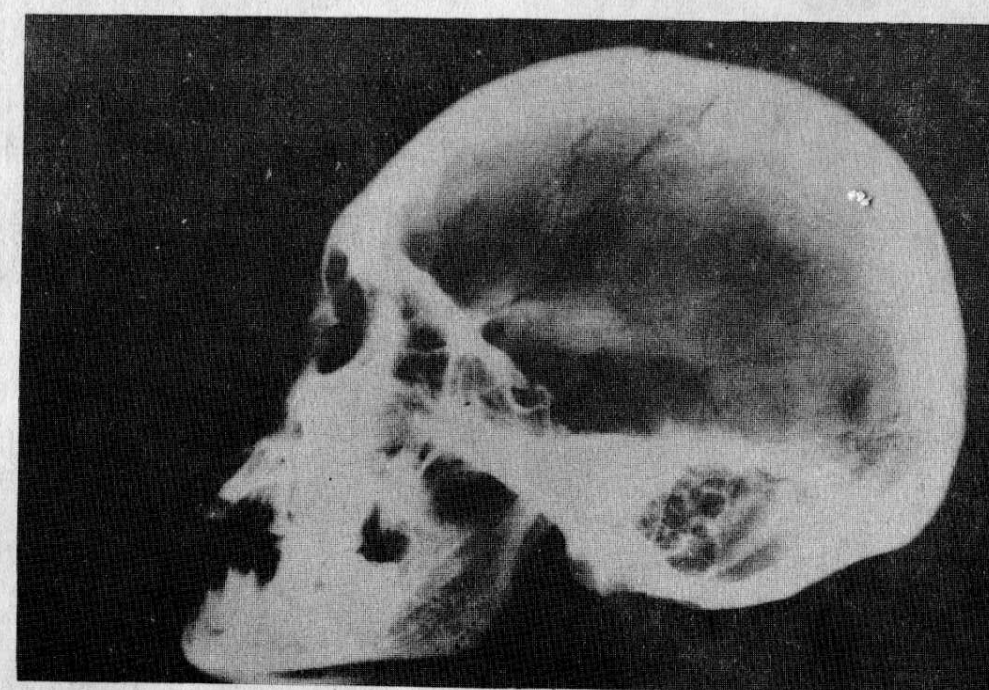

Fig. 3

Fig. 1 Caso No. 1: Trepanación parietal derecha y plastia. Obsérvese la separación de las suturas. Figs. 2 y 3: Caso No. 1: Radiografías lateral y antero-posterior. La zona radio-opaca, corresponde a la cranioplastia. 


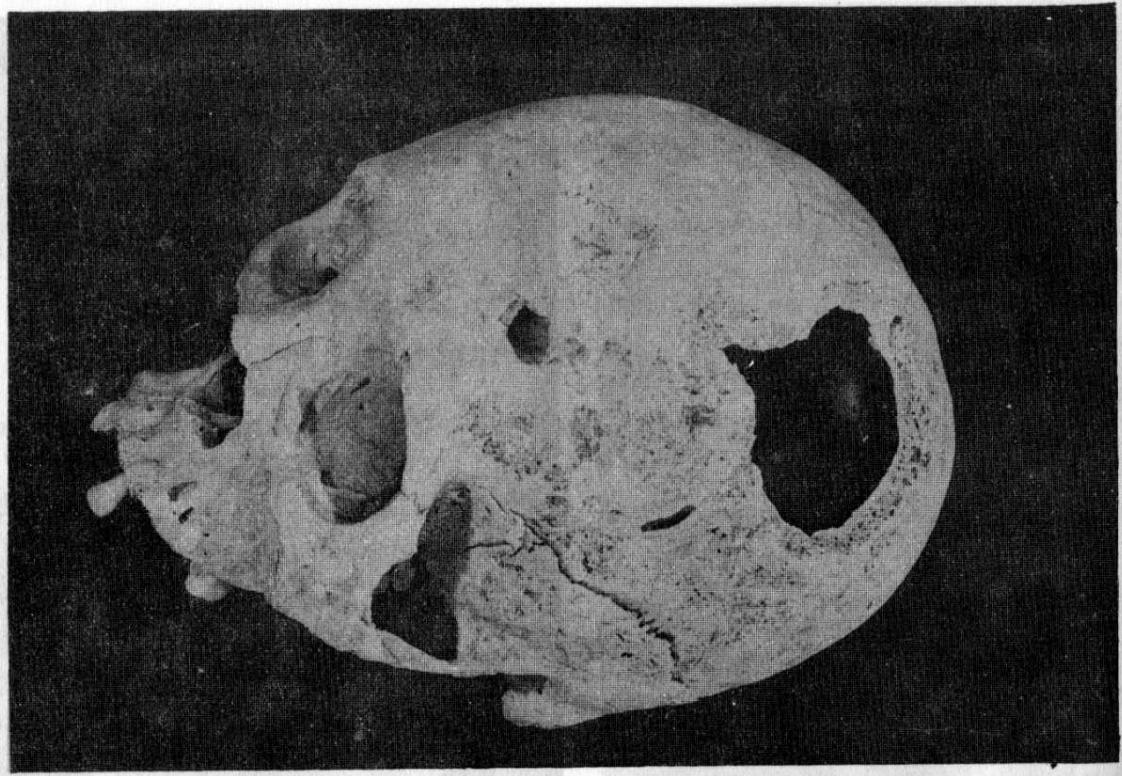

Fig. 4 Caso No. 2: Defecto quirúrgico con pérdida de sustancia parietal izquierda

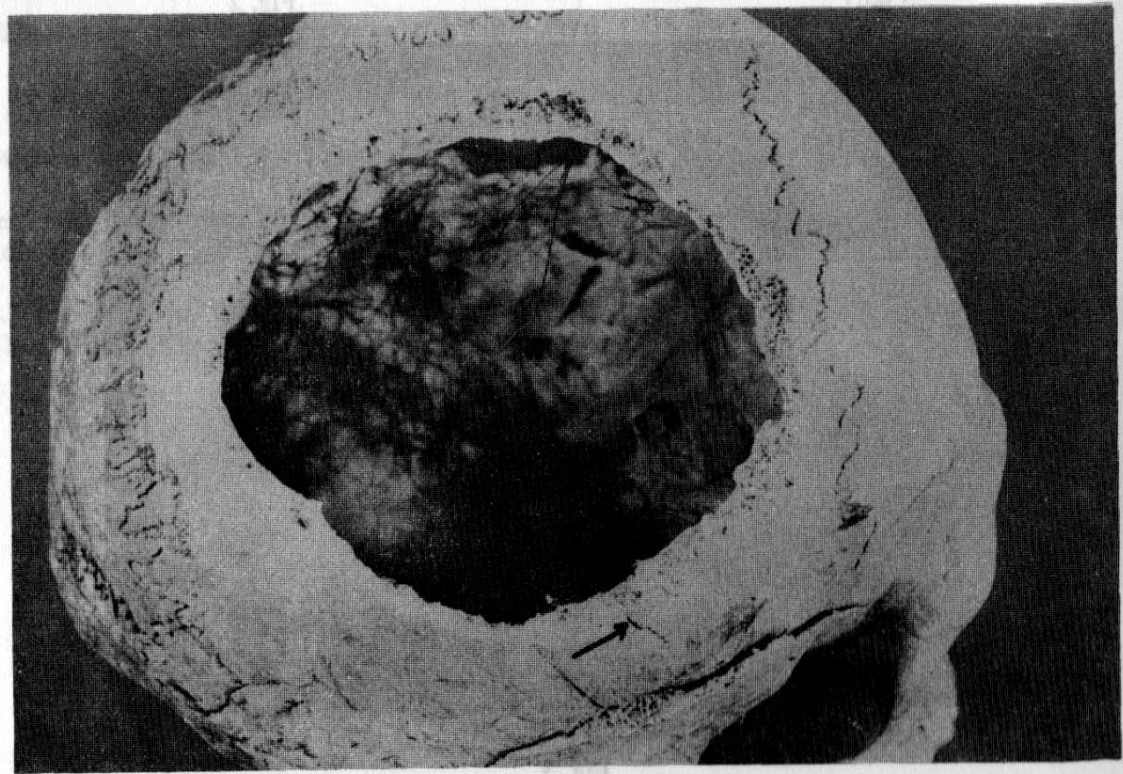

Fig. 5 Caso No. 3: Defecto quirúrgico parietal derecho. Obsérvese línea de fractura que se extiende hasta la sutura temporo-parietal y halo anémico. 